\title{
Speaking with a forked tongue about multilingualism in the language policy of a South African university
}

\author{
Bassey E. Antia ${ }^{1}$ D $\cdot$ Chanel van der Merwe ${ }^{1,2}$
}

Received: 6 May 2017 / Accepted: 16 November 2018 / Published online: 18 December 2018

(c) Springer Nature B.V. 2018

\begin{abstract}
As part of a broader student campaign for 'free decolonized education', protests over language policies at select South African universities between 2015 and 2016 belied widespread positive appraisals of these policies, and revealed what is possibly an internal contradiction of the campaign. The discourse prior to the protests (e.g. "excellent language policies but problematic implementation"), during the protests (e.g. silence over the role of indigenous African languages in the "Afrikaans must fall" versus "Afrikaans must stay" contestations), and after the protests (e.g. English becoming a primary medium in some institutional policy reviews) warrant attention to critical literacy in language policy scholarship. Based on a theoretical account of speaking with a forked tongue, this article analyzes the language policy text of one South African university. The analysis suggests, simultaneously, why similar policies have tended to be positively appraised, why students' calls for policy revisions were justified, but why the changes clamoured for arguably amount to complicity in self-harm.
\end{abstract}

Keywords Language policy - Systemic functional linguistics $\cdot$ Tactical polyvalence University of the Western Cape · South African higher education · Multilingualism

\section{Introduction}

Official language policy and language practices at universities were one ground for the student protests across university campuses in South Africa between 2015 and 2016. At the height of these protests, and under the rallying banner of 'a free decolonized education', students had registered grievances related to funding, sculpted statues and other symbols of European imperialism, outsourcing of support services,

Bassey E. Antia

bantia@uwc.ac.za

1 Department of Linguistics, University of the Western Cape, Bellville, South Africa

2 Department of Applied Language Studies, Nelson Mandela University, Port Elizabeth, South Africa 
the invisibilization of African knowledge pools in the taught curriculum, among others (Mkhize 2018; Van Reenen 2018). The language dimension of the protests was mainly about dislodging Afrikaans on those campuses where the institutional language policy had made it co-official with English or institutional practices had de facto made Afrikaans primus inter pares. Thus, on several campuses (e.g. Stellenbosch University, University of Pretoria, University of the Free State, Northwest University), there were language protests and/or litigation over proposed changes to language policy texts. One consequence of the protests is the ongoing review of the language policies in higher education, with the national review foregrounding indigenous African languages, while, paradoxically, certain institutional reviews (Stellenbosch, Pretoria, Northwest) are according English an exclusive status of primary medium of instruction, with other languages playing a supportive role. Mwaniki (2018: 31), for instance, observes that in "some universities, the \#AfrikaansMustFall movement was countered by the \#AfrikaansSalBly (Afrikaans will stay) movement. With the language policy shifts to English at the University of the Free State, University of Pretoria, University of South Africa and Stellenbosch University having been confirmed through judicial review, the issue of \#AfrikaansSalBly has since become a moot point."

The agitation over university language policies would have come as a surprise to many observers, but for somewhat different reasons. First, several of the campuses on which the language protests took place were thought to have evolved innovative practices, such as educational or classroom interpreting. Du Plessis (2006), for instance, had noted that universities which were historically Afrikaans-speaking (e.g. Pretoria, Stellenbosch, Northwest) seemed to be doing the most to promote multilingualism. Second, with a few exceptions (e.g. Stroud and Kerfoot 2013; Antia 2015), the widespread scholarly view prior to the protests was that universities in the country had reasonably good language policy documents consistent with the country's social transformation goals, and that the major problem was either the lack of implementation of explicit provisions or the failure by stakeholders to act on the implementation spaces prised open by the policies (DHET 2015; Kaschula 2013; Makalela and McCabe 2013). Third, it was surprising that the students were largely mute about the role of indigenous African languages in higher education. In a YouTube video documenting the protests at Stellenbosch University (Luister 2015: https://www.youtube.com/watch?v=sF3rTBQTQk4), black student interviewees in part hinged the clamour for English on the arguable premise of it being a leveller, disadvantaging them (as first language speakers of African languages) as equally as it does students who are first language speakers of Afrikaans.

As remarked by Mwaniki (2018) and Makalela (2018), there has regrettably been very little research into the language dimension of the student protests. More broadly, it would in fact seem that the discourse prior to the protests (e.g. excellent policies but problematic implementation), during the protests (e.g. silence over the role of indigenous African languages in the "Afrikaans must fall" versus "Afrikaans must stay" demonstrations), and after the protests (e.g. English as primary medium in several policy revisions) warrant attention, especially from critical literacy perspectives. Following Andreotti (2014), we view critical literacy as the nexus between writing/reading and knowledge, power and subjectivities. Inspired by her 
illustrations of relevant questions in the context of the classroom, the above account raises a number of concerns: in whose name and on the basis of what insight was the determination made that university language policies were excellent? Why was it that the students did not discern, or make an issue of, the marginalization of indigenous African languages, especially in light of their broader concern with the power asymmetries informing arrangements in higher education and to which the decolonization call was offered as a rejoinder? How did the students arrive at a position of complicity in linguistic and cognitive self-harm, given documented challenges of English language tuition (e.g. Van Rooy and Coetzee-Van Rooy 2015; Dyers 1998; Desai 2016)?

To address these questions, this article analyzes the language policy text of a South African university. Against the backdrop of the above concerns, the article seeks to specifically understand the following: (1) how this policy text (and others like it) responds to a set of competing voices (see "Of voice and forked tongues" section below); (2) how linguistic choices are deployed to encode an interplay of voices, and what the effects of these choices are; (3) how the pattern of dominant meanings in the policy text is resemiotized from discourses at an earlier stage of the policy development process; and (4) what the implications of this critical literacy endeavour could be as policies are being revised or conceptualized. It should become evident at the end of this case analysis why language policies have tended to be positively appraised, why students' calls for policy revisions during the protests were justified, but why the changes clamoured for arguably amount to complicity in self-harm.

In the first section of this article, we will describe the South African university language policy landscape, focusing in particular on the language policy text of the University of the Western Cape, our case study. Secondly, as an approach to a critical literacy analysis for language policy research, theoretical perspectives on speaking with a forked tongue will be developed, drawing on such notions as voice (Couldry 2010), tactically polyvalent discourses (Foucault 1990), strategic action (Habermas 1984), and engagement within Appraisal theory (Martin and White 2005). Thirdly, the Materials and methods will be described. Fourthly, data will be presented and analyzed to show what voices are responded to, through what linguistic choices and to what ends. Fifthly, to explain some of the preceding analyses, institutional discourses preceding the development of the policy text are examined. The examination draws on resemiotization (Iedema 2003) and semiotic remediation (Prior and Hengst 2010). In the conclusion, among others, implications are drawn for advocacy and oversight in a context of the rewriting of university language policies.

\section{Language policy at South African universities}

As a result of South Africa's British, Dutch and Afrikaner colonial past, the making of language policies in the country's university system largely proceeded for some 80 odd years until the 1990s without reference to the languages of African and Coloured students (see below for an explanation of the term 'Coloured'). The English-Dutch bilingualism ushered in by the Union of South Africa in 1910 saw 
the universities in existence at the time (University of Cape Town, Stellenbosch University and the University of South Africa) transform from English-medium only institutions to bilingual English-Dutch (Antia 2017a). Afrikaans subsequently took over from Dutch. Under apartheid (1948-1994), the national official languages at South African universities were English and Afrikaans, neither of which was a home language of, for instance, the country's majority African population.

Post-1994, the first democratically elected government in South Africa launched a raft of measures intended to build a transformed state that would shed the legacies of the country's apartheid past. One of such measures was the Language Policy on Higher Education (Ministry of Education 2002). The Language Policy on Higher Education (LPHE) required individual universities to formulate their own language policies in line with the directive principles of state policy as enshrined in a number of regulatory instruments, including the then new Constitution of 1996. The Constitution, among others, declares eleven languages as official; commits the state to developing and advancing the use of indigenous African languages; requires all government agencies to ensure parity of esteem for, and equitable treatment of, all eleven official languages; conditionally guarantees the rights of individuals in public educational institutions to receive education in an official language or official languages of their choice. Under the LPHE, universities had to ensure that, in their respective policies and operations, the erstwhile official languages of Afrikaans and English would no longer be "a barrier to access and success" (Ministry of Education 2002: 5). While explicitly making it an infringement for institutions to exclusively employ Afrikaans as medium of instruction, the LPHE also required previously English-medium universities to commit to the use of the country's nine indigenous languages that had become official. These indigenous languages were to be developed and used as academic languages.

The national directives themselves were not unproblematic in the sense that relevant provisions were tempered with clauses related to several factors: feasibility, e.g. section 29(2) of the Constitution which states that "everyone has the right to receive education in the official language or languages of their choice in public educational institutions where that education is reasonably practicable"; a desire not to upset the apple cart too quickly, e.g. section 15.1 of the LPHE states that: "In the light of practical and other considerations it will be necessary to work within the confines of the status quo until such time as other South African languages have been developed to a level where they may be used in all higher education functions"; etc.

Our chosen institutional case study, the University of the Western Cape (UWC), like other universities, interpreted the national directive on institutionalizing multilingualism by performing its own delicate balancing acts, given its own set of local realities. On one level, there were the official languages (English, Afrikaans and isiXhosa) of the province in which UWC is situated. On another level, there were considerations such as internal demographics, the institution's history, and the aspirations of its leadership. Let us flesh out the latter set of considerations.

UWC was established in 1959 as a bilingual, English and Afrikaans institution, to cater for the higher education needs of the population group in South Africa referred to by an increasingly contested term, 'Coloureds' (that is, people of mixed African, European and Asian descent). De facto, however, Afrikaans was employed at the 
inception of the institution; a standardized variety based on the usage of educated white Afrikaners was used, not the varieties employed by the Coloured community in the Western Cape Province. By the 1980s, staff and student protests over discriminatory apartheid policies in all spheres of national life had culminated in the radical decision of the University (taken in 1987) to formally reject the racial premises of the institution's founding, and to open the doors of learning to all, irrespective of race or ethnicity (Antia 2015). As subsequent events would show, rejecting the premises of the institution's founding also meant rejecting Afrikaans, which was associated with the apartheid government.

With the decision to open up admission to students of all races, large numbers of especially black, isiXhosa-speaking, students began to enrol. A changed student composition accentuated the language question at the institution. Highlighting an aspect of the question, the Rector and Vice-Chancellor at the time said the following:

We have asked staff to consider whether we should not consider that we have circulars and forms at university in the first place in English, given the national makeup and composition of the institution and also the spirit that drives us to be a national institution. In practice it often happens that circulars go out in the first place in Afrikaans. It is seldom that we send out documents in both languages. While there is no-one at UWC who does not understand English, there is a considerable number of people who still have difficulty with Afrikaans. It is only practical that, where one wants to build an institution, to use a language which binds people together. (UWC 1989: 41).

We see the changing institutional demographics, the anti-apartheid politics of the day, and the aspirations of the institutional leadership, all combining to reshape the language question at UWC and to set in motion processes (surveys, consultations, reports) that would culminate in the language policy text that is analyzed in this article.

Conjecturally, in a democratic setting, a language policy text arising within this context would be shaped by the variety of voices of both external and internal stakeholders it would have to attempt to accommodate, for example: a voice for overall multilingualism associated with the national government (as recorded in the Constitution and the LPHE), the provincial government, and with concerned students and staff; a voice for isiXhosa specifically, associated with concerned staff and Xhosa students who stand to benefit from the language they speak at home being a basis for them to engage with knowledge at university; a voice for Afrikaans, linked to staff and students with a facility in this language, and keen to preserve a status quo in which this language was (for a time) the only de facto official language of the institution; a voice for English, equally associated with students and staff members, and critically with the identity politics and aspirations of the leadership at the time to build a national institution with an international appeal.

Although the specifics would differ, these are broadly the sorts of concerns to which university language policies have traditionally had to respond. A key issue for this article, then, is to examine how these contending voices are responded to in UWC's language policy text. To do this, we first develop a theoretical account of speaking with a forked tongue. 


\section{Of voice and forked tongues}

Voice, according to Couldry (2010: 1), denotes, among others, a "perspective on the world that needs to be acknowledged." It is particularly useful for encoding the clash of perspectives, the engineered trumping of one perspective over others, especially in "contexts where long-entrenched inequalities of representation need to be addressed" (Couldry 2010: 1). In problematizing and theorizing the notion of voice, Couldry points out that an important contradiction in contemporary neoliberal society is that, increasingly, "voice is persistently offered, but in important respects denied or rendered illusory" (Couldry 2010: 1). Couldry proceeds to offer a view of voice as value, which implies attending to the conditions for its effectiveness, and to arrangements that guard against its being undermined. Legitimacy is accorded voice when voice is not just offered but also allowed to matter or to become effective.

Foucault, Habermas, and other scholars would term the oxymoronic voicing and devoicing as discursive strategy. Foucault (1990) elaborates on the notion of discourses being tactically polyvalent, by which he means they are built from or contain disparate voices (e.g. thesis positions vs. antitheses). He writes that discourses "are tactical elements or blocks operating in the field of force relations; there can exist different and even contradictory discourses within the same strategy" (Foucault 1990: 101-102; our italics). Rather than bifurcations of the world of discourse into accepted versus excluded voice, what is of interest, according to Foucault, is the distribution of these voices in any particular sample of discourse from the standpoint of their effects-which may be different according to the speaker, their position of power and their institutional context (Foucault 1990: 100). Read together with the other Foucauldian idea of power as hegemony through accommodation, the account on the tactical polyvalence of discourses in a sense grounds the notion of texts being able to speak with a forked tongue. Tactical polyvalence also makes an approach to discourse analysis that is rooted in critical literacy important.

Although Foucault would be critical of Habermas' bifurcation of communication strategies, Habermas does provide some insight into the phenomenon of forked tongue. According to Habermas (1984), in using language to interact, social actors may do so in one of two ways: to coordinate actions collaboratively, consensuallythis is termed 'communicative action'; or to achieve their own narrow, unshared goals - this is termed 'strategic action' (Gross 2010: 337-338; Scambler and Britten 2001: 52-55). Strategic action, in turn, can be openly or covertly accomplished. One form of covert strategic action that is particularly relevant to speaking with a forked tongue would be evaluated as deception or manipulation, and would involve a speaker or a text moving from communicative action (shared goals) to strategic action (narrow goals), without the recipient being aware of such a shift. The text presumably foregrounds shared goals initially, then slides subsequently into articulating unshared goals. Clearly, a particular type of reading that is rooted in critical literacy is needed to detect the sliding from communicative to strategic actions.

Bakhtin's work is also relevant to theorizing the notion of speaking with a forked tongue. Bakhtin's construct of double-voiced discourse incorporates two 
voices; it "serves two speakers at the same time and expresses simultaneously two different positions [...]. And all the while these two voices are dialogically related, they - as it were-know about each other [...] and are structured in this mutual knowledge of each other" (Bakhtin 1981: 324). Bakhtin (1999) has also argued that a text maintains different kinds of intertextual or dialogical ties with previous or prospective texts (presuming other texts to be known, polemicizing with them, building on them). This work has been drawn upon in Appraisal Theory (Martin and White 2005; Hart 2014) to account for how the different voices accommodated within a given text are made to relate to one another. Within the subsystem of Appraisal Theory called engagement, the manner in which voices in heteroglossic texts (texts that accommodate alternative voices) are made to relate to one another has been described as either expansive or contractive. With expansion, accommodated voices are presented as legitimate and credible alternatives to be built on or explored. With contraction, certain voices are included only to be polemicized with or suppressed. Using Couldry's account as interpretative framework, when alternative voices are accommodated in expansive ways, they all have value, with the conditions for their effectiveness being attended to. In contrast, when alternative voices are accommodated in contractive ways, voice is denied value. It is with contraction that we likely see the phenomenon of speaking with a forked tongue as well as the Habermasian covert strategic action.

\section{Materials and methods}

This study draws data from three main sources: UWC's language policy (2003), a language policy discussion document, and a reading experiment around the language policy text. Most of the data, however, come from the language policy, which is a 3-page, 783-word document. Following a preamble, the policy makes provisions for: teaching, learning and assessment; internal communication; external communication; academic literacy and language acquisition. To highlight the importance of critical literacy in language policy analysis, a reading experiment was conducted. In a postgraduate class on multilingualism, a convenience sample of 10 students rated the policy in terms of their perceptions of how supportive it was of multilingualism under two conditions: prior to, and after, reading a draft of two sections of this article: "Of voice and forked tongues" section and parts 1-4 of "How a language policy text may speak with a forked tongue" section.

In order to address the question of how meaning and structure in a policy text may be historicized, unfolding from earlier discourses, an archival document, the "Language Policy Discussion Document" was analyzed. At the time of its development presumably in the late 1980s, this document was intended to get the discussion going on the language question (cf. quotation from the Rector and Vice-Chancellor in "Language policy at South African universities" section). The first two sections of this document (questionnaires and background) are analyzed from the standpoint of resemiotization to show how the policy bears the traces of meanings from an early stage of thinking about language policy to the final text that was published about a decade later. Resemiotization is "about how meaning making shifts from context 
to context, from practice to practice, or from one stage of a practice to the next" (Iedema 2003: 41). There is the related notion of semiotic remediation, which is about how signs and meanings "are re-represented and reused across modes, media, and chains of activity" [Prior et al. (2006) as cited in Prior and Hengst (2010: 1)].

A set of tools for critical literacy was applied to determine how the policy text responds to contending positions and, especially, to unlock the linguistic choices employed in encoding differential commitment to voices. We draw out the meaning-making potentials of the following notions within the policy text: process type, demodalisation, activation, modal verbs and conditional clauses. We explain each of these in turn.

In the system of transitivity of Halliday's systemic functional linguistics (SFL), a process is an activity, a way of being or a happening (Halliday 1994; Eggins 2004; Ravelli 2000). Processes may be Material, Mental, Verbal, Relational, Existential and Behavioural; in addition, they determine participant types. Thus, a Material process would have such participants as Actor, Goal, Circumstance, among others; a Behavioural process would have a Behaver and a Behaviour, and so on. In the context of the envisaged analysis, meaning potential resides in the choice of one process type rather than another. A Material process (e.g. build) conveys a strong sense of doing, of acting on possibilities. Used in contexts that are comparable, it may be interpreted as conveying greater commitment than a Mental process (e.g. believe) or lesser commitment than a Relational process of the Identifying or the Attributive subtype (e.g. the Attributive "multilingual" in the clause "the university is multilingual"). Relational processes, in other words, establish an identity as a matter of fact. On the borderline between a Mental and a Material process is the Behavioural process (e.g. dream) which we could interpret, depending on the context, as either exhibiting weaker commitment or even stronger commitment if the Behaviour is construed as reflecting an internalization of a set of identifying characteristics. Several voices may, thus, be accommodated within a text, but the different values placed on them may be read off from a pattern of choice of processes. The hypothetical "We will build multilingualism into all aspects of our institutional life", using a Material process build, may be perceived as qualitatively different in the way it values multilingualism compared to "We are a multilingual institution"-which uses are, a Relational process of the Attributive type, and which makes multilingualism a characteristic of the institution, a goal that has already been attained rather than one that has to be worked on.

Demodalisation removes agency in propositions in order to suggest non-contestation or a fait accompli. It distances "commander from commandee" (Iedema 2000: 50). Demodalisation, according to Iedema (2000: 50), is used to "de-emphasize the interpersonal nature of the must-ness by objectifying control" and to "fix the desired action as a non-negotiable objectified and already existing thing". The semiotic potential of demodalisation in our analytical context lies in offering a view of which of the voices accommodated within a policy text is considered non-contestable, thus more valued. In contrast to demodalisation, activation underscores agency and places action in the realm of contestability. With activation "social actors are presented as the active, dynamic forces in an activity" (van Leeuwen 1996: 43), and the moment actors are identified in a proposition, a window (however tiny) is opened 
to interrogate these actors' credentials, attributes, or intentions. As with other tools above, it is potentially of interest to see what voices or provisions in the language policy text are identified with actors and which are demodalised.

Modal verbs communicate the manner in which a speaker or a writer qualifies their propositions as probability, obligation, suggestion, and so on (Quirk et al. 1985). There is semiotic potential in a pattern of application of modal verbs to voices in a language policy text. One might be interested in ascertaining if certain voices are positioned as obligations and others as mere possibilities or suggestions. Conditional clauses, as part of the umbrella category of conditionals, "state in what kind of possible scenarios a given proposition is true" (von Fintel 2011: 2); in other words, they specify the requirements that have to be met for a certain action to be performed. There is meaning potential in a pattern of application of conditionals to specific voices. Within the preceding theoretical account on voice and forked tongue, the use of these analytical tools enables us to determine where, in the policy text, "voice is persistently offered, but in important respects denied or rendered illusory" and where voice is genuinely valued (Couldry 2010: 1).

\section{How a language policy text may speak with a forked tongue}

As if to demonstrate Foucault's point about tactical polyvalence, UWC's language policy (UWC 2003) does not appear to exclude any of the contending voices outlined earlier. The policy in fact responds by accommodating all three corresponding languages (Afrikaans, English, isiXhosa). It recognizes Afrikaans (mentioned 12 times), English (17 mentions) and isiXhosa (12 mentions) as the institution's official languages. Similar to Grin's (2010) outline of purposes of language use in universities, the main body of the policy (that is, after the preamble) provides for these three languages under the following areas: teaching, learning and assessment; internal communication; external communication; and language proficiency programmes. Sample provisions are as follows:

- "Regarding the languages used in the setting of tasks, assignments, tests and examinations, English, Afrikaans and Xhosa should be used wherever it is practicable to do so."

- "Regarding the languages in which texts are available, efforts should be made to provide alternatives and options in Afrikaans, English and Xhosa wherever it is practicable and academically desirable to do so."

On the surface, the policy accommodates all three languages and appears to value all three equally. A critical literacy analysis grounded in Foucault's tactical polyvalence acknowledges, and requires an investigation into, the prospect that voice may be offered "but in important respects denied or rendered illusory" (Couldry 2010: 1). In subsequent sections, this prospect is investigated as are the underlying linguistic choices. For ease of analysis, the contending positions are framed below as commitment to English versus commitment to multilingualism (Afrikaans, isiXhosa with or without English). 


\section{Is there differential commitment to English versus multilingualism enacted through the choice of process types?}

In Table 1, we present provisions from the policy regarding English versus multilingualism in order to probe the meaning potential of processes employed.

In the English provisions on Table 1, we see that the verbal group comprises a modal auxiliary shall which communicates obligation or the mandatory nature of the provision, and the verb be used here as an Identifying process. The use of an Identifying process equates both sides of a proposition. Factoring in the modal auxiliary, example 1 for instance would be processed as follows: the language of examinations mandatorily equals English, and vice versa. Example 2 would be parsed as: the official version mandatorily equals English and vice versa. Besides the Circumstancial or hedging, normally, the English provisions all communicate a strong sense of commitment, or of the institution's identification with English. We see, in effect, a pattern of Identifying processes conveying what the institution has come to be.

In contrast, such strength of commitment is strikingly absent in the verbal group used for the multilingual provisions. The verb phrases comprise, among others, the more contingent or non-mandatory modal auxiliary should which communicates suggestion or possibility and processes that are Material (e.g. use, made) or Behavioural (seek). Meaning that would ordinarily have been read into Material processes (that is, commitment to act to achieve, say, an aspiration) is weakened either by the non-mandatory modal auxiliary should or by the Circumstantial progressively. Collectively, the multilingual provisions communicate a set of contingent actions, unlike the English provisions which communicate mandatory requirements and identify the institution with English. In a manner reminiscent of Foucault's and Habermas' concepts, this analysis shows how voice is given to both pro-English positions as well

Table 1 Contrasting the language thrusts of provisions on the basis of process types

English provisions Multilingual provisions

(1) The language in which tasks, assignments, tests and examinations should be completed shall be English

(2) The main language of internal communication for academic and administrative purposes shall be English

The language used for external communication shall normally be English

(4) In all cases, the official version shall be the English version
(5) Regarding the language used in the setting of tasks, assignment, tests and examination, English, Afrikaans and Xhosa should be used wherever it is practicable to do so

(6) Regarding the languages [in which texts are available], efforts should be made to provide alternative options in Afrikaans, English and Xhosa

(7) Regarding the languages students use in their self-directed learning processes and activities, department should actively seek to appoint some student tutors who can assist students in Xhosa and/or Afrikaans, as well as English

(8) However, the university will progressively make important information available in Afrikaans, English and Xhosa 
as pro-multilingualism perspectives (English, Afrikaans and isiXhosa), and how the latter is weakened through the choice of process types. Whether this critical reading amounts to making a mountain of a mole hill or not will depend on the systemic nature of our other findings.

\section{Is there differential commitment to English versus multilingualism enacted through demodalisation and activation?}

In Table 2, we present a number of clauses, which are then analyzed to determine if on the basis of demodalisation and activation we can discern differential commitment of the policy writers to English versus multilingualism.

From Table 2, we see that with provisions on English (1-4), there is a suppression of agency or actors (demodalisation), a strategy interpretable as an attempt to "de-emphasize the interpersonal nature of the must-ness by objectifying [the] control" and to "fix the desired action as a non-negotiable objectified and already existing thing" (Iedema 2000: 50). Demodalisation makes provisions monovocal and undialogized, takes them out of the realm of Bakhtinian polemicisation. It also seems to have implications for implementation. A provision such as (4), "The main language of internal communication for academic and administrative purposes shall be English" does not invite discussion; it is a fait accompli. With provisions on multilingualism, we see several patterns - all in contrast to the non-negotiability of the English provisions: explicit activation $(7,9,11,12,13)$; activation with, or implied in, a conditional $(8,10)$; demodalisation which is weakened by a conditional clause as well as modal verbs that communicate suggestion, rather than obligation (as in $5,6)$. The conditional clause "wherever it is practicable to do so" in provision 5 on Table 2 around the setting of assessment tasks, places a burden of proof on whoever requires multilingual assessment or seeks to offer it, but of course the standard of (what constitutes) proof is contestable.

In sum, we see how demodalisation and activation are able to inform a critical reading, which in turn reveals biases which may otherwise have been difficult to detect. While demodalisation in the English-only provisions removes agency and suggests non-contestation, this effect is tempered in the context of provisions on multilingualism, many of which are also characterized by activation which thus places action in the realm of contestability. Again, multilingualism is offered a voice just as English is; but in the important aspect of implementation, the voice of the former is weakened (unlike that of the latter) and framed as negotiable and contestable.

\section{Is there differential commitment to multilingualism versus English enacted through a pattern of use of conditional clauses?}

Conditionals in African language policy documents are well known and have been popularized by especially Bamgbose under the label 'escape clauses' (Bamgbose 1991). These escape clauses have become convenient means for policy avoidance, that is, non-implementation of policy provisions. What is interesting about conditional clauses in the current context is the opportunity to observe how they function 
Table 2 Contrasting the language thrusts of provisions on the basis of demodalisation and activation

English provisions

(1) The language in which tasks, assignments, tests and examinations should be completed shall be English

(2) All students will have access to entry-level courses aimed at strengthening their English oral and aural skills and improving their academic literacy in English

(3) All students will have access to support services to assist them in developing their academic literacy in English

(4) The main language of internal communication for academic and administrative purposes shall be English
Multilingual provisions

(5) Regarding the languages used in the setting of tasks, assignments, tests and examination, English, Afrikaans and Xhosa should be used wherever it is practicable to do so

(6) Regarding the languages in which texts are available, efforts should be made to provide alternative options in Afrikaans, English and Xhosa

(7) If lecturers are competent users of other language, they are encouraged to use these languages in addition to main languages of teaching if such a practice facilitates communication or discussion

(8) If individuals request information from the university in either Afrikaans or Xhosa, the information will be translated into that language, and the translated version will be sent to the individual accompanied by the English version

(9) Regarding the languages students use in their self-directed learning processes and activities, departments should actively seek to appoint some student tutors who can assist students in Xhosa and/or Afrikaans, as well as English

(10) If departments for whatever reason deem it necessary, or because research into the needs of the client group reveals a clear need, Afrikaans and Xhosa translations of formal communication should be made available, provided that it is practicable to do so

(11) The university undertakes to make language acquisition courses in Afrikaans, English and Xhosa available to both administrative and lecturing staff

(12) However, the university will progressively make important information available in Afrikaans, English and Xhosa

(13) The university shall have staff available to assist enquirers in Afrikaans, English and Xhosa

in the provisions for different languages. See Table 3 for relevant data from UWC's language policy.

In Table 3, the conjunction "unless" used in the English provisions has the effect of making English the default language for external communication and for assessments. The effect of the conditional clauses introduced by "unless" is to place something akin to evidential burden (adducing evidence to make a case) on whoever seeks to dislodge English from its default role. The extent to which using English amounts to insensitivity needs to be demonstrated, and evidence (which can 
Table 3 The use of conditionals in the language policy provisions

\begin{tabular}{|c|c|}
\hline English provisions & Multilingual provisions \\
\hline $\begin{array}{l}\text { The languages used for external } \\
\text { communication shall normally be } \\
\text { English, unless sensitivity to the } \\
\text { recipient requires use of another } \\
\text { language }\end{array}$ & $\begin{array}{l}\text { Regarding the languages used in the setting of tasks, assignment, } \\
\text { tests and examinations, English, Afrikaans and Xhosa should be } \\
\text { used wherever it is practicable to do so }\end{array}$ \\
\hline \multirow[t]{5}{*}{$\begin{array}{l}\text { Unless otherwise negotiated } \\
\text { between a student or a class } \\
\text { and a lecturer, the language [in } \\
\text { which tasks, assignments, tests } \\
\text { and examinations should be } \\
\text { completed] shall be English }\end{array}$} & $\begin{array}{l}\text { Regarding the languages in which texts are available, efforts should } \\
\text { be made to provide alternative options in Afrikaans, English and } \\
\text { Xhosa, wherever it practicable to do so }\end{array}$ \\
\hline & $\begin{array}{l}\text { If lecturers are competent users of other languages, they are encour- } \\
\text { aged to use these languages in addition to main languages of } \\
\text { teaching if such practice facilitates communication or discussion }\end{array}$ \\
\hline & $\begin{array}{l}\text { If departments for whatever reason deem it necessary, or because } \\
\text { research into the needs of the client group reveals a clear need, } \\
\text { Afrikaans and Xhosa translation of formal communication should } \\
\text { be made available, provided that it is practicable [to do so] }\end{array}$ \\
\hline & $\begin{array}{l}\text { If individuals request information from the university in either } \\
\text { Afrikaans or Xhosa, the information will be translated into that } \\
\text { language }\end{array}$ \\
\hline & $\begin{array}{l}\text { Should a speaker prefer to speak in Afrikaans or Xhosa, use will be } \\
\text { made of informal interpreting, if it is practicable [to do so.] }\end{array}$ \\
\hline
\end{tabular}

of course be challenged) needs to be provided that consensus has been reached on using a language other than English. For the multilingual provisions, the evidential burden to be discharged is more around desirability (request, preference) or feasibility that is demonstrated through onerous processes. In sum, a base is firmly secured for English as default. Although a voice is offered multilingualism, the associated conditions are such that this voice can easily become mute. We see coming through quite clearly Bakhtin's (1981) point about the two voices in double-voiced discourse being aware of each other and being "structured in this mutual knowledge of each other" (Bakhtin 1981: 324). The English provisions allow space for alternative language arrangements if the burden of necessity is discharged. They, in a sense, take issue with or polemicize with multilingualism. The multilingual provisions acknowledge English as default to be overwritten only under specific conditions.

\section{Are promises textually made and textually broken? Comparing the preamble versus the body of the policy as sites for voicing multilingualism}

The UWC language policy, like many other policies, begins with a preamble. A preamble specifies the underlying principles of a policy as well as its broad goals (Varga 1971). A university's language policy can be seen as an instrument for creating or projecting a certain self-image of the institution. It therefore becomes interesting to 
determine the extent to which this image is, for instance, detached from, or connected to, the actual contents of the policy.

The preamble to UWC's language policy reads as follows (we have numbered the analytical clauses and italicized processes):

(1) The University of the Western Cape is a multilingual university, alert to its African and international context.

(2) It is committed to helping nurture the cultural diversity of South Africa and build an equitable and dynamic society.

(3) This language policy relates to one aspect of that commitment.

(4) It attempts to guide institutional language practice

(5) so that it furthers equity, social development and a respect for our multilingual heritage. (UWC Language Policy 2003: 1).

As the following analysis shows, this preamble strongly identifies the institution with multilingualism and diversity. In clause 1, the linking verb is functions as a Relational process of the Attributive kind which makes the first participant ('The University of the Western Cape') the Carrier and 'a multilingual university...' the Attribute. In this instance, UWC is attributing to itself the characteristic of a "multilingual university" that is alert to its presumably multicultural environment. In clause 2, the verb is is also a Relational process of the Attributive kind that allows the Carrier (UWC) to ascribe to itself the role of nurturing the cultural diversity of South Africa. It is instructive that nurturing is used here, as it is presumably taken over from the context of bringing up children and tending to them in a caring and protective environment. Thus, in this context, the university expresses its dedication to care for and protect cultural diversity. It is also significant that the verb, build (communicating self-exertion to achieve an aspiration), is used. The unfolding picture is one of an institution strongly assigning to itself values of multilingualism and multiculturalism.

Clause 3 uses the Identifying process relates to specify the language dimension of the more general aspiration of an equitable and dynamic society. Thus, in clause 3 , the participant language policy is the Token, while one aspect of that commitment is the Value-referring to a commitment to nurturing diversity and promoting equity. In clauses 4 and 5, Behavioral processes are employed, almost as if to indicate that the characteristics constituting the institutional identity are giving rise to or being translated into certain natural actions. Clause 4 uses the Behavioural process attempts to guide to communicate what the language policy would have to do, while clause 5 uses furthers to communicate a Behaviour around equity and respect for multilingual heritage.

In sum, the five clauses of the preamble perform two major functions. The Relational processes of the Attributive and Identifying types establish the fact of the University's multilingualism, diversity and equity; the Behavioural processes specify the almost naturally ensuing efforts to realize these objectives. The preamble, then, paints a picture of multilingualism being incorporated into all spheres of language use at the University.

When the foregoing is read in light of the earlier analyses of differential commitments in the body of the policy, we see quite clearly that both the preamble and 
the body of the policy create a text that is appropriately and severally described as double-voiced; as constituting tactically polyvalent discourses; as illustrating strategic communication; and so on. It can be argued that the impression created in the preamble is certainly not one of a voice being reluctantly or conditionally offered multilingualism. The analysis of the differential commitment to English versus multilingualism in the body of the policy text would seem to have yielded data that point to a textual breaking in the body of the policy of promises made in the text of the preamble.

\section{How easy is it to detect speaking with a forked tongue in the language policy text and to misrecognize complicity in self-harm?}

Previous sections have made much of the critical literacy potentials of process types, demodalisation and activation, and conditionals. It is no doubt a reflection of the effectiveness of more modern forms of the exercise of discursive power and a validation of preceding analyses that 10 postgraduate students in a lecture on language policy rated UWC's language policy text highly in terms of its commitment to multilingualism; on a second rating, however, they drastically revised their assessments downwards after they had read a draft of "Of voice and forked tongues", "Is there differential commitment to English versus multilingualism enacted through the choice of process types?", "Is there differential commitment to English versus multilingualism enacted through demodalisation and activation?", "Is there differential commitment to multilingualism versus English enacted through a pattern of use of conditional clauses?" and "Are promises textually made and textually broken? Comparing the preamble versus the body of the policy as sites for voicing multilingualism" sections. See Table 4.

We see from Table 4 that, while at the outset only three respondents had relatively low assessments of the policy's commitment to multilingualism (rating it 1 or 2 ), the number of low assessments increased to eight on a second rating. With all the conceivable limitations of this reading experiment, the findings suggest an important point: the linguistic features of policy texts can influence or shape students' views of the adequacy of the policies. While the texts themselves do not undermine human agency, they conceivably have an impact on the kind of consciousness that activates the exercise of that agency.

Table 4 Evolved ratings of students' perceptions of how committed the language policy is to multilingualism

\begin{tabular}{lll}
\hline Rating scales & $\begin{array}{l}\text { Number selecting scale(s) } \\
\text { prior to intervention }\end{array}$ & $\begin{array}{l}\text { Number selecting } \\
\text { scale(s) after interven- } \\
\text { tion }\end{array}$ \\
\hline 1 and 2 & 3 & 8 \\
3 & 4 & 1 \\
4 and 5 & 3 & 1 \\
Total & 10 & 10 \\
\hline
\end{tabular}

Rating scale: from 5 (highest perception of commitment to multilingualism) to 1 (lowest perception of commitment to multilingualism) 
There is complicity in self-harm when students (especially of African and Coloured backgrounds) praise, or clamour for, a language policy that privileges English, which is widely considered an albatross. Van Rooy and Coetzee-Van Rooy (2015) provide an excellent overview of South African studies on university students' English and academic literacies. All the studies accord with the view that "the twin challenge of academic language and language of instruction (English) remains one of the most significant barriers to success and one which universities must address in a systematic and sustained manner" [Council on Higher Education quoted by Van Rooy and Coetzee-Van Rooy (2015: 32)]. There are, for instance, concerns around academic reading in English (at any or all of three levels, viz. surface, applied and critical) as well as around writing.

This national think-tank (i.e. the Council on Higher Education, CHE) elsewhere acknowledges that the country's universities were designed "for a largely homogenous intake with middle-class cultural capital and mother tongue as the language of instruction" (CHE 2013: 63). That African and Coloured students were excluded from the system design, is obvious from the CHE's 2006 cohort study data showing that, in terms of graduating in regulation time, the percentage of African students (20\%) and Coloured students (24\%) was, respectively, less than half and slightly more than half of the percentage of White students (44\%); with respect to attrition within degree regulation time, the percentage for African students (42\%) and for Coloured students (47\%) was higher than the $33 \%$ for White students.

Given these academic performance hierarchies, often reproducing the hierarchization of (dis)advantage immanent in broader society, it is enigmatic at least from educational standpoints that the students' campaign would canvass support for English. It arguably amounts to complicity in self-harm, one that is borne out of some misrecognition or displaced understanding, for students who are non-home users of English (typically African and Coloured) to do the following: (1) support a position on language of instruction that is mute on their own languages; (2) assume that that the use of English is a leveller, disadvantaging White Afrikaans-speaking students as much as themselves. Although there are several reasons why this assumption is tenuous, one would be that White Afrikaans-speaking students, in contrast to a majority of African and Coloured university students, would have attended wellresourced schools and have been exposed to quality teaching of English as a subject, making them "comparatively successful in this medium at ... tertiary level" (du Plessis 2005: 38).

\section{What are the practical implications of a policy speaking with a forked tongue?}

It would seem interesting to determine whether there are real world consequences of UWC's policy text, which preceding sets of analyses have shown to be speaking with a forked tongue. In other words, are institutional language practices in any way affected by the above characterizations of the policy? In a study of the same institution, Stroud and Kerfoot (2013) come to a set of conclusions that accord with the implications of the above analyses. Generally, they note that "[m]ultilingual provision is thus barely visible as an issue at UWC" (p. 399). From their observation, in 
spite of the language policy, "a very real impression emerges of "business as usual", along with marginal and conditional acceptance of a deviation from the normative linguistic order of English". Specifically with respect to instructional arrangements, they note that "teaching and learning practices at UWC can be characterised as moving students towards a "monolingual straitjacket" [...], in which other languages are invisible" (p. 399).

With respect to the multilingualism in the institution's linguistic landscape, a study by Antia (2015) captures the same social structuring of English versus multilingualism seen in preceding analyses. Where there is trilingual signage, the "model of multilingual signage often used is one that has been labelled "fragmentary multilingualism"' (p. 579). In other words, isiXhosa and Afrikaans would only have a fragment of the information contained in English, even with safety-critical notices.

Consistent with the policy and the preceding discussion document, both of which essentially transfer the responsibility for action on whoever desires alternative arrangements, it is often in the area of individual initiatives that some of the high profile visibility for multilingualism has come-some, thanks to the enablement of the policy text, others fairly independently of it. Banda (2007) has noted how, in peer study sessions, students deploy their rich multilingual repertoires to make sense of curricular content. Students' translanguaging in lecture halls, communicating or siding among themselves in hushed tones across language varieties while the lecturer is teaching, has also been described (Antia 2015, 2017b). Although practices of translanguaged siding are not referred to in the policy, they show how students agentively refashion an understanding of multilingualism that subverts the compartmentalization of languages in the policy text.

One individual initiative that has attracted both institutional and national recognition derives its warrant from the policy text. Ongoing work by Antia and Dyers (2016, 2017) is offering both written and audio (as podcasts) lecture materials to students enrolled in their third year module in linguistics in several languages: English, isiXhosa, Afrikaans and Kaaps, the latter employed by many students in the Coloured community. Assessments are also being conducted in these languages as well. These efforts are in response to relevant policy provisions, as may be recalled from "How a language policy text may speak with a forked tongue" section.

While this initiative readily illustrates how enabling a policy might be in spite of its inadequacies (cf. Hornberger and Johnson 2007 on implementational spaces), it is easy to underestimate (as Hornberger and Johnson in fact point out) just how much effort is required. It is easy to forget that initiatives such as these could also be construed as an admission of power asymmetries over which not much can be done. Let us illustrate both of these points. Firstly and unsurprisingly, the absence of the kind of enablement which a firm commitment to multilingualism provides, is one reason why attempts by colleagues to replicate aspects of the above initiative in such departments as Women and Gender Studies, History and Language Education have at best had rather qualified success (Antia's personal communication with the respective initiators, November 2017-June 2018). Secondly, the national student protests directed at Afrikaans saw students deploying their power to change the policy status quo, rejecting in this instance what for them was presumably the cold comfort of whatever accommodation or agentive space was afforded by the policy. 
In sum, then, it would seem that practices at the institution rather exceptionally reflect findings of the textual analysis of the policy. In the next section, we seek explanations for the findings of the policy's features.

\section{Historicizing meaning-making in language policy analysis}

UWC's language policy text is the outcome of both external and internal processes of meaning-making. In "Language policy at South African universities" section, we highlighted the problematic nature of the national initiatives (the Constitution, the Language Policy on Higher education) to which UWC's language policy responds. Traces of those national discourses (around feasibility and not wanting to upset the applecart too quickly) have also been seen in UWC's policy. Internally, UWC's policy is the outcome of a chain of activities (meetings leading to the development of discussion documents and survey instruments from which emanated responses that were synthesized into written reports, etc.). Driven initially by a Senate Working Group on the Language Question and, subsequently, by structures linked to the defunct Academic Development Centre, these activities unfolded over several years from the late 1980s.

In using an archival document to explain how internal meaning-making processes shape the policy as seen in the results from the preceding analyses, we are illustrating the historicization or unfolding of meaning-making in language policy development. As seen earlier, these concerns are matters of resemiotization or semiotic remediation.

The section of the "Language Policy Discussion Document" on staff and student questionnaires, like other sections, are heteroglossic texts, that is, in the sense of incorporating items that evince concern for English and for multilingualism simultaneously. However, these texts are reminiscent of Habermas' strategic action in that they accommodate Afrikaans and isiXhosa in ways that are contractive. So, in the very questions that were to launch a chain of activities we find features being resemiotized or semiotically remediated in the eventual policy text some 10 odd years later.

First, in the questionnaires, all the hypotheticals and scenarios regarding the choice of a formal academic language involve English, and to some extent Afrikaans (in a transitional role) but never isiXhosa. Consider the following items from, respectively, the student and staff questionnaires: "If English were to become the main medium of instruction, what kind of help and provision would you like in adapting to this?" "Would you support the idea of parallel English and Afrikaans classes in some courses at first-year level as a way of helping Afrikaans-speaking students to adjust to English as a medium of instruction?"

Second, opportunities evoked for the use of Afrikaans alone or together with isiXhosa are tied to (or conditional upon) decisions on English and are couched in discourses of sensitivity or care. The above two questions, like many others, speak of help and support to adapt and to adjust. There are of course ideological undertones: why are questions not also based on the strengths of the isiXhosa-speaking 
students, so they are not portrayed as vulnerable at every turn and always having to be helped and supported to adapt and to adjust?

Third, while many of the questions incorporate a "justify your answer" clause, the main stem differs in its open or close-ended nature, depending on which language is involved. There are more open-ended, thus burdensome, questions requiring answers that make a case for isiXhosa and Afrikaans than those that make a case for English. In other words, a lot more is demanded of respondents who wish to make a case for isiXhosa and Afrikaans. Contrast the question above which has a hypothetical (where a case has to be made for languages other than English) with the close-ended "Do you think that students who score below a certain minimum in an English language proficiency test should be compelled to do a Foundation English course?" Admittedly, there are contexts in which open-ended questions are valued. Thus, in healthcare, a professional's aversion to asking open-ended questions of patients tends to be interpreted negatively as the exercise of power. However, in our current context, asking open-ended questions is interpreted as disabling, especially when these questions are asked of respondents who are suspected to be diffident users of English, which is the language in which the questionnaire is administered.

Read in the context of the preceding sections, the above analysis shows how ideas that began as questions, albeit biased consistently towards English, get ultimately 'ported' to the language policy texts as statements of differential commitment towards English versus multilingualism. From the hypothetical "If English were to become the main medium of instruction...' of the discussion document, we ultimately end up in the policy text with a demodalised "The language in which tasks, assignments, tests and examinations should be completed shall be English". It is particularly striking to see how the link between the fortunes of Afrikaans and isiXhosa being dependent on hypotheticals and scenarios involving English are ported to the pattern of use of conditionals as described in "Is there differential commitment to multilingualism versus English enacted through a pattern of use of conditional clauses?" section (on differential commitment enacted through the use of conditionals). Similarly, the pattern of open- and close-ended questions in the questionnaire, seen above as implying different efforts in responding, is very reminiscent of what was seen in the same "Is there differential commitment to multilingualism versus English enacted through a pattern of use of conditional clauses?" section as the evidential burden (adducing evidence to make a case) placed on whoever sought to dislodge English from its default role. We deduce from the foregoing that the meanings, thinking and ideas in the questionnaires already adumbrated the eventual policy text, and that there must have been precious little by way of alternative meanings during the consultative processes to modify the meanings of the initiators of the policy development process.

What was described in "Are promises textually made and textually broken? Comparing the preamble versus the body of the policy as sites for voicing multilingualism" section as promises made but broken, following a comparison of the policy's preamble and body, may be seen as in part ported from the pattern of skewed interplay of English versus multilingualism in the background as well as other sections of the "Language Policy Discussion Document". The background section begins with the same preamble theme of concern for diversity. It poses the UWC language 
question as follows: "Can we continue with English and Afrikaans as the official media of instruction? Are we meeting the linguistic needs of a growing and changing student population?" To be clear, the reference here is to the increasing number of especially black and isiXhosa-speaking students enrolling at the institution, not to students who have Afrikaans or English as home languages. By some unfathomable logic, meeting these linguistic needs is interpreted as a need for initiatives in English. The final paragraph of the background shuts down the initial opening for diversity when it says:

we have more to say about English than about Afrikaans and African languages. This is partly because we feel that an intervention in the interests of our students' English language development is a priority at this stage and partly because English is now the most widely used language at UWC in academic settings. However, we would welcome any criticisms and perspectives which speakers of other languages would like to bring into the discussion. We feel that we urgently need to get the process of discussion and decision-making under way. We have no intention of putting speakers of Afrikaans and Xhosa (or any other language for that matter) at a disadvantage in this process.

It is difficult to resist reading this background as illustrating a shift from Habermas' communicative action to strategic action. In sum, on analysis, a small fragment of a document that contains some of the earliest thoughts around how to organise a language policy development process, reveals how meanings move through stages in policy development.

\section{Conclusion and implications}

In this article, the question of critical literacy in university language policies in South Africa was posed against the backdrop of student protests which, besides their own internal contradictions regarding language, belied the widespread positive appraisals of these policies. We have drawn on an eclectic framework to theorize the notion of speaking with a forked tongue and we have also drawn on eclectic sources including systemic functional linguistics to construct a tool box for a critical literacy analysis of this double-voicing. Through our UWC case study (where admittedly the contemporary question is not one of the dominance of Afrikaans), insight has been provided into why these policies probably elicited widespread positive appraisal and why students' calls for policy revisions were justified. We have also implied that the change clamoured for by students - that is, English — arguably amounts to complicity in cognitive self-harm.

Our results show how a policy product and its underlying process, both premised on the need for inclusiveness and both feting multilingualism initially, end up excluding to some extent the very group whose needs they purport to have derived their warrant from. The analysis reads essentially as a story of how Afrikaans was dislodged and English enthroned in a process which had as its raison d'être isiXhosa-speaking students. 
If the foregoing analysis has attended to two of Tollefson's (2006) senses of 'critical' in language policy - the sense dealing with a reading that acknowledges the interest-laden nature of policy texts and the sense on how language may be used to conceal dominant interests-it now remains for us to attend to the third sense, that is, to consider relevant advocacy aimed at addressing/reducing social inequality. As university language policies are being revised, it would be important to actively cultivate the participation of diverse stakeholder groups in organizing relevant processes, and to allow for the introduction of viewpoints and evidence which may not be well known. Cognizant of the dominant discourse for English and the environment of linguistic and cultural self-deprecation, it would be disingenuous to simply fashion policies based on questionnaire responses from respondents. Also, the language varieties employed should be enabling, not disabling; in this regard, consideration needs to be given to translating discussion documents and policy drafts. In discussions, careful consideration needs to be given to strategies such as outlined in this piece through which voice may be offered but simultaneously muffled or made difficult to articulate.

The content and wording of policy provisions can be relied upon to legitimize subsequent actions, and critical awareness-raising cannot escape drawing attention to some of these actions. For instance, language policy provisions can become the warrant for the creation of language jobs within an institution or for the development of learning resources in language varieties; policy provisions can become a platform for reconfiguring the linguistic cultural capital on which institutions are based and without which, in its statistics of success and failure, the educational system reproduces some of the very same patterns of inequality evident in larger society (Bourdieu 2003).

More generally, the study has shown that modern forms of the exercise of discursive power in language policy texts may not be enacted in ways that are perhaps reminiscent of Franco's suppression of other languages in favour of Spanish in Spain (Miller and Miller 1996) or Abbé Grégoire's 1794 programmatic language report for Post-revolutionary France, infamously titled 'Report on the necessity and means of suppressing local dialects and of generalizing the use of the French Language in France' (Antia and Brann 1991). Unlike these traditional modes of exercise of discursive power, which have tended to lead to language policy texts that were largely monovocal and undialogized, our analysis shows discursive power as responding to competing interests in language policy through accommodation-into which a complex and barely visible system of valuation is built.

Acknowledgements The authors gratefully acknowledge suggestions made by anonymous reviewers as well as funding from the South African National Institute for the Humanities and Social Sciences. Paul Duncan and Lynn Mafofo are also thanked for comments on parts of the paper.

\section{References}

Andreotti, V. (2014). Critical literacy: Theories and practices in development education. Policy \& Practice: A Development Education Review, 19, 12-32. 
Antia, B. E. (2015). University multilingualism: A critical narrative from the University of the Western Cape, South Africa. Journal of Multilingual and Multicultural Development, 36(6), 571-586.

Antia, B. E. (2017a). University multilingualism: Modelling rationales for language policies. In R. Kaschula, P. Maseko, \& E. Wolff (Eds.), Multilingualism and intercultural communication: A South African perspective (pp. 157-181). Johannesburg: Wits University Press.

Antia, B. E. (2017b). Shh, hushed multilingualism! Accounting for the discreet genre of translanguaged siding in lecture halls at a South African university. International Journal of the Sociology of Language, 243, 183-198.

Antia, B. E., \& Brann, C. M. B. (1991). Report on the necessity and means of suppressing local dialects and of generalizing the use of the French Language in France. Being a translation of Abbé Grégoire's 1794 programmatic report for Post-revolutionary France, presented to the French National Convention. As appendix to: Brann, C. M. B. (1991). National language policy and planning: France 1789, Nigeria 1989. History of European Ideas [special issue on Rise and Development of National European Languages, C. M. B. Brann, editor], 13(1/2), 97-120.

Antia, B. E., \& Dyers, C. (2016). Epistemological access through lecture materials in multiple modes and language varieties: The role of ideologies and multilingual literacy practices in student evaluations of such materials at a South African university. Language Policy, 15(4), 525-545.

Antia, B. E., \& Dyers, C. (2017). Affirming the biliteracy of university students: Current research on the provision of multilingual lecture resources at the University of the Western Cape. In D. M. Palfreyman \& C. van der Walt (Eds.), Academic Biliteracies-Translanguaging and multilingual repertoires in higher education settings (pp. 113-141). Bristol: Multilingual Matters.

Bakhtin, M. M. (1981). The dialogic imagination: Four essays. Austin: University of Texas Press.

Bakhtin, M. M. (1999). The problem of speech genres. In A. Jaworski \& N. Coupland (Eds.), The discourse reader (pp. 98-107). London: Routledge.

Bamgbose, A. (1991). Language and the nation. Edinburgh: Edinburgh University Press.

Banda, F. (2007). Study groups and peer roles in mediated academic literacy events in multilingual educational contexts in South Africa. Stellenbosch Papers in Linguistics, 37, 1-21.

Bourdieu, P. (2003). Cultural reproduction and social reproduction. In P. Jarvis \& C. Griffin (Eds.), Adult and continuing education: Major themes in education (pp. 173-184). London: Routledge.

CHE. (2013). A proposal for undergraduate curriculum reform in South Africa: The case for a flexible curriculum structure. Pretoria: Council on Higher Education.

Constitution of the Republic of South Africa. (1996). Pretoria: Government Press.

Couldry, N. (2010). Why voice matters: Culture and politics after Neoliberalism. London: Sage.

Desai, Z. (2016). Learning through the medium of English in multilingual South Africa: Enabling or disabling learners from low income contexts? Comparative Education, 52(3), 343-358.

DHET. (2015). Report on the use of African languages as mediums of instruction in higher education. Pretoria: Department of Higher Education and Training.

Du Plessis, S. (2005). Multilingual preschool learners: A collaborative approach to a communication intervention. D.Phil. thesis, University of Pretoria.

Du Plessis, T. (2006). From monolingual to bilingual higher education: The repositioning of historically Afrikaans-medium universities in South Africa. Language Policy, 5, 87-113.

Dyers, C. (1998). An investigation into current attitudes towards English at the University of the Western Cape. Per Linguam, 13(1), 29-37.

Eggins, S. (2004). Introduction to Systemic Functional Linguistics (2nd ed.). New York: Continuum International Publishing Group.

Foucault, M. (1990). The history of sexuality. London: Penguin Books.

Grin, F. (2010). Managing languages in Academia: Pointers from education economics and language economics. Paper presented at the professionalising multilingualism in higher education conference, Luxembourg, February 4, 2010.

Gross, A. G. (2010). Systematically distorted communication: An impediment to social and political change. Informal Logic, 30(4), 335-360.

Habermas, J. (1984). The theory of communicative action (Vol. 1). Boston: Beacon Press.

Halliday, M. A. K. (1994). An introduction to functional grammar (2nd ed.). London: Edward Arnold.

Hart, C. (2014). Discourse, grammar and ideology: Functional and cognitive perspectives. London: Bloomsbury.

Hornberger, N., \& Johnson, D. (2007). Slicing the onion ethnographically: Layers and spaces in multilingual language and education policy and practice. TESOL Quarterly, 41(3), 509-532.

Iedema, R. (2000). Bureaucratic planning and resemiotisation. In E. Ventola (Ed.), Discourse and community: Doing functional linguistics (pp. 47-70). Tubingen: Narr. 
Iedema, R. (2003). Multimodality, resemiotization: Extending the analysis of discourse as multi-semiotic practice. Visual Communication, 2(1), 29-57.

Kaschula, R. (2013). Multilingual teaching and learning models at South African Universities: Opportunities and challenges. Seminar Presentation at Rhodes University, March 2013.

Luister. (2015). Available at: https://www.youtube.com/watch?v=sF3rTBQTQk4.

Makalela, L. (2018). "Our academics are intellectually colonised": Multi-languaging and fees must fall. Southern African Linguistics and Applied Language Studies, 36(1), 1-11.

Makalela, L., \& McCabe, R. (2013). Monolingualism in a historically black South African university: A case of inheritance. Linguistics and Education, 24(4), 406-414.

Martin, J. R., \& White, P. R. R. (2005). The language of evaluation: Appraisal in English. Basingstoke: Palgrave Macmillan.

Miller, H., \& Miller, K. (1996). Language policy and identity: The case of Catalonia. International Studies in Sociology of Education, 6(1), 113-128. https://doi.org/10.1080/0962021960060106.

Ministry of Education. (2002). Language policy for higher education. Pretoria: Ministry of Education.

Mkhize, D. (2018). The language question at a historically Afrikaans university: Access and social justice issues. Southern African Linguistics and Applied Language Studies, 36(1), 13-24.

Mwaniki, M. (2018). South African higher education language politics post \#RhodesMustFall: The terrain of advanced language politics. Southern African Linguistics and Applied Language Studies, 36(1), 25-36.

Prior, P., \& Hengst, J. (2010). Introduction: Exploring semiotic remediation. In P. Prior \& J. Hengst (Eds.), Exploring semiotic remediation as discourse practice (pp. 1-28). New York: Palgrave Macmillan.

Quirk, R., Greenbaum, S., Leech, G., \& Svartvik, J. (1985). A comprehensive grammar of the English language (1st ed.). London: Longman.

Ravelli, L. (2000). Getting started with functional analysis of texts. In L. Unsworth (Ed.), Researching language in schools and communities (pp. 27-64). London: Cassell.

Scambler, G., \& Britten, N. (2001). System, lifeworld and doctor-patient interaction. Issues of trust in a changing world. In G. Scambler (Ed.), Habermas, critical theory and health (pp. 45-67). London, New York: Routledge.

Stroud, C., \& Kerfoot, C. (2013). Towards rethinking multilingualism and language policy for academic literacies. Linguistics and Education, 24(4), 396-405.

Tollefson, J. W. (2006). Critical theory in language policy. In T. Ricento (Ed.), An introduction to language policy. Theory and method (pp. 42-59). Malden, MA: Blackwell.

UWC. (1989). UWC: A University in Action. Bellville: University of the Western Cape.

UWC. (2003). University of the Western Cape language policy. Approved by Council, June 2003.

Van Leeuwen, T. (1996). The representation of social actors in discourse. In C. R. Caldas-Coulthard \& M. Coulthard (Eds.), Text and practices: Readings in critical discourse analysis (pp. 32-70). London: Routledge.

Van Reenen, D. (2018). Communicative rationality in conflicted language ecologies post \#RhodesMustFall at the University of the Free State. Southern African Linguistics and Applied Language Studies, 36(1), $57-71$.

Van Rooy, B., \& Coetzee-Van Rooy, S. (2015). The language issue and academic performance at a South African university. Southern African Linguistics and Applied Language Studies, 33(1), 31-46.

Varga, C. (1971). The preamble: A question of jurisprudence. Budapest: Maison d'éditions de l'Académie des sciences de Hongrie.

von Fintel, K. (2011). Conditionals. In K. Von Heusinger, C. Maienborn, \& P. Portner (Eds.), Semantics: An international handbook of meaning (Vol. 2, pp. 1-34). Berlin, Boston: de Gruyter Mouton.

Bassey E. Antia is a professor of Linguistics at the University of the Western Cape. Antia's major areas of research emphasis include language policy and multilingualism in higher education and terminology. He is the author of Terminology and language planning (2000) and the editor of Terminology and indeterminacy (2007), both published by John Benjamins Publishers.

Chanel van der Merwe is a lecturer in the Department of Applied Language Studies Nelson Mandela University. Her interests lie in the fields of critical discourse analysis, language policy, multilingualism and higher education studies. For her envisaged doctoral studies, van der Merwe proposes to examine how discourses internal and external to higher education shape university language policies. 